
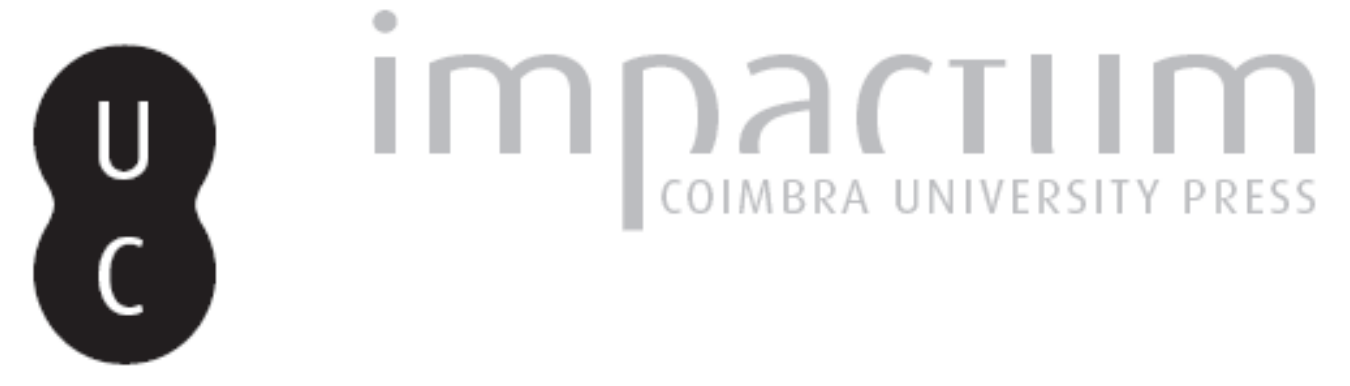

\title{
Diplomatas franceses e diplomatas espanhóis frente a Comunidade Europeia: algumas observações para uma história política comparada das administrações diplomáticas
}
Autor(es): $\quad$ Trouvé, Matthieu
Publicado por: Centro de Informação Europe Direct de Aveiro; Centro de Estudos Interdisciplinares do Século XX
URL persistente:
URI:http://hdl.handle.net/10316.2/33984
DOI: $\quad$ DOl:http://dx.doi.org/10.14195/1647-6336_11_13

Accessed : $\quad$ 26-Apr-2023 01:49:56

A navegação consulta e descarregamento dos títulos inseridos nas Bibliotecas Digitais UC Digitalis, UC Pombalina e UC Impactum, pressupõem a aceitação plena e sem reservas dos Termos e Condições de Uso destas Bibliotecas Digitais, disponíveis em https://digitalis.uc.pt/pt-pt/termos.

Conforme exposto nos referidos Termos e Condições de Uso, o descarregamento de títulos de acesso restrito requer uma licença válida de autorização devendo o utilizador aceder ao(s) documento(s) a partir de um endereço de IP da instituição detentora da supramencionada licença.

Ao utilizador é apenas permitido o descarregamento para uso pessoal, pelo que o emprego do(s) título(s) descarregado(s) para outro fim, designadamente comercial, carece de autorização do respetivo autor ou editor da obra.

Na medida em que todas as obras da UC Digitalis se encontram protegidas pelo Código do Direito de Autor e Direitos Conexos e demais legislação aplicável, toda a cópia, parcial ou total, deste documento, nos casos em que é legalmente admitida, deverá conter ou fazer-se acompanhar por este aviso.

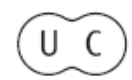


DEBATER

A EUROPA

jul-dez 2014

QUE EUROPA(S)?

CONTEXTOS E DESAFIOS 


\title{
Diplomatas franceses e diplomatas espanhóis frente a Comunidade Europeia: algumas observações para uma história política comparada das administrações diplomáticas
}

\author{
Matthieu Trouvé \\ Maître de conférences en histoire contemporaine \\ Sciences Po Bordeaux \\ E-mail : matthieutrouve@hotmail.com
}

\begin{abstract}
Resumo
Durante as três décadas da Cominidade económica europeia (CEE) constituiu-se uma cultura política nas administrações que impregnou os diplomatas europeus, neste caso os diplomatas franceses e espanhóis, e que levou à formação de uma elite favorável à construção europeia, mesmo se não existe uma unanimidade de atitudes e de posições com relação a essa construção. Os grandes debates europeus - Europa federal / Europa das Patrias, Europa política / Europa económica, Europa supranacional / Europa intergovernamental - foram no centro das atenções dos diplomatas. Esse estudo tenta mostrar que exitem muito mais pontos em comum entre diplomatas franceses e espanhóis do que diferenças nas atitudes frente a CEE, devido a uma cultura administrativa e política.
\end{abstract}

Palavras-chave: Diplomacia; Espanha; França; Comunidade europeia; política exterior

\begin{abstract}
During the three decades of the European Economic Community (EEC), a political culture grew up in the European administrations witch became very strong for the European diplomats, particularly the French and Spanish diplomats. This culture leads to the creation of an elite in favour of the European construction, even if the sensibilities and the positions towards Europe are not unanimous. The important debates about European construction federal Europe / Europe of nations, political Europe / free-trade Europe, supranational Europe
\end{abstract}


/ intergovernmental Europe - have found a big echo in the diplomatic administrations. This paper tries to aim the points in common between French and Spanish diplomats in relation with their attitudes towards the EEC.

Keywords: Diplomacy; Spain; France; European Community; foreign policy

A proposta deste artigo é tentar analisar as atitudes e as sensibilidades dos diplomatas franceses e espanhóis frente a Comunidade europeia numa perspectiva comparada. Uma aproximação nova na história da construção europeia levou os historiadores à observar o papel das administrações diplomáticas nacionais no processo de integração europeia. Assim, a historiografía britânica e francesa sobre essas questões fez um emfoque sobre as temáticas de impulsos, resistências, continuidades nas culturas administrativas diplomáticas, analisando, por exemplo, o papel dos ministérios de Relações exteriores e dos departamentos administrativos na construção europeia ${ }^{1}$.

Nos quereríamos aqui seguir examinando a visão da construção europeia nas administrações diplomáticas, centrando o olhar nos funcionários diplomáticos, no tema das atitudes humanas, das sensibilidades políticas desses homems, num largo período, da formação da Comunidade económica europeia (CEE) até a criação da União europeia (UE). Por outro lado, nossa visão propõe também uma análise comparativa entre Franceses e Espanhóis a pesar das diferenças entre dois países que não tem o mesmo rítmo e nem a mesma relação com a construção europeia. Os trabalhos universitários sobre os diplomatas ou as administrações se concentraram efectivamente em estudos meramente nacionais ${ }^{2}$.

A nossa hipótese de trabalho é a seguinte : durante as três décadas da CEE constituiuse uma cultura política nas administrações que impregnou os diplomatas europeus, neste caso os diplomatas franceses e espanhóis, e que levou à formação de uma elite favorável à construção europeia, mesmo se não existe uma unanimidade de atitudes e de posições com relação a essa construção. Esse estudo tenta mostrar que exitem muito mais pontos em comum entre diplomatas franceses e espanhóis do que diferenças nas atitudes frente a CEE, devido a uma cultura administrativa e política.

Pelo menos três dificuldades metodológicas surgem no estudo. A primeira é o problema da generalização de situações individuais complexas e ambíguas. Como identificar e definir atitudes pro-europeias de diplomatas que podem mudar de opinião ou de

\footnotetext{
${ }^{1}$ Ver os estudos de Maurice Vaïsse, Gérard Bossuat, Georges-Henri Soutou, Laurence Badel, Stanislas Jeannesson, Pierce Ludlow, Laurent Warlouzet, Matthieu Osmont.

2 BADEL, Laurence, JEANNESSON, Stanislas, LUDLOW, Pierce - Les administrations nationales et la construction européenne, une approche historique (119-1975). Bruxelles: Peter Lang, 2005.
} 
comportamento com respeito à construção europeia ? Tomando em consideração um exemplo francês, o embaixador René Massigli é favorável a uma relação privilegiada entre França e Grã Bretanha, queria apoiar a entrada do Reino Unido na CEE, mas era claramente oposto a Comunidade europeia de defesa (CED). Outro exemplo, José Luis Cerón, antiguo negociador do tratado de comércio entre o seu país e o Mercado comum, é a favor de uma abertura económica da Espanha, mas também está ao serviço do regime franquista, foi ministro do Comércio e não pretendía defender uma abertura política do seu país.

A segunda dificuldade metodológica é relacionada ao estatuto dos diplomatas. São funcionários do Estado e têm normalmente dever de neutralidade ${ }^{3}$. Portanto, fica difícil observar e identificar oficialmente atitudes e posições políticas de diplomatas cuja principal missão é de servir o Estado, de contribuir à definição de um posicionamento internacional. $\mathrm{O}$ caso de Hervé Alphand é um bom exemplo aqui; a pesar de ter uma proximidade com as ideias do general de Gaulle e de ser considerado como um anti-federalista, ele teve que negociar o tratado CED num sentido favorável à França ${ }^{4}$.

Por fim, o último problema metodológico é o das fontes. Os documentos dos ministérios de Assuntos exteriores franceses e espanhóis devem ser completados pelo estudo de fontes orais e de testemunhos publicados, como Memórias de embaixadores. Aqui, o comfronto dessas fontes é mais do que nunca indispensável. Tal estudo está, portanto, conectado à varias histórias: história das relações internacionais, clássica, história administrativa, história política, história cultural. A metodología privilegía a história comparada, a história cruzada, mas ao querer analisar sentimentos e sensibilidades também podemos referir-nos à história transnacional ${ }^{5}$. Essa comunicação não pretende ser exaustiva. É apenas o começo de uma reflexão mais amplia sobre o corpo diplomático francês e espanhol e deve ser aprofundada. Queremos aqui somente levantar algumas observações e presentar algumas conclusões provisórias de um trabalho qua ainda não acabou devido ao largo período (1957-1992) de estudo escolhido.

\section{I- A formação de um discurso sobre Europa}

\footnotetext{
${ }^{3}$ KESSLER, Marie-Christine - Les ambassadeurs. Paris: Presses de Sciences Po, 2012. 413 p.

${ }^{4}$ ALPHAND, Hervé - L'Étonnement d'être. Journal, 1939-1973. Paris: Fayard, 1977.

${ }^{5}$ Ver MINARD, Philippe - Globale, connectée ou transnationale : les échelles de l'histoire. In Esprit, $\mathrm{N}^{\circ} 400$, (décembre 2013) p. 20-32 ; revista Monde(s). Histoire, espaces, relations - Le débat transnational, $\mathrm{XIX}^{\mathrm{e}}$ XX ${ }^{\mathrm{e}}$ siècle, A. Colin. $\mathrm{N}^{\circ} 1$ (mai 2012).
} 
A formação dos diplomatas segue na França como na Espanha os mesmos caminhos. A vía de acesso mais clássica à carreira diplomática é o concurso : o Quai d'Orsay ou o concurso da Escola nacional de Administração (ENA) criada em 1945 na França, o concurso da Escola diplomática criada em 1942 na Espanha. No caso espanhol, a Escola diplomática propõe um ensino técnico e geral, ela tem como missão a formação dos diplomatas e dá aulas e conferências sobre Europa e direito internacional. A escola abriu-se aos temas europeus nos anos 1950-1960, mas sempre com a intenção de formar funcionários ao serviço do Estado franquista ${ }^{6}$.

Não existe homogeneidade entre os diplomatas franceses ou espanhóis : pelo contrario, existem muitas diferenças devido à idade, à trajetória e à entrada na carreira diplomática - antes ou depois da guerra civil na Espahna, antes ou depois da Segunda Guerra mundial na França; antes ou depois da Quinta República na França, antes ou depois da ditadura franquista na Espanha. Segundo esses critérios, existiriam pelo menos três categorias de diplomatas franceses : uma velha geração que trabalha sobre temas europeus começou a sua carreira nos anos 1930 (Jean Chauvel, René Massigli), outros entraram no ministério de Assuntos exteriores depois da Segunda Guerra mundial (François Seydoux, René Massigli), outros ainda entraram no ministério por causa da guerra e ao lado do general de Gaulle (Maurice Couve de Murville, Hervé Alphand, Olivier Wormser, Alexandre Parodi) e têm em comum uma forte cultura gaullista, sendo ésta definida como uma cultura de guerra e uma cultura política ${ }^{7}$. Encontramos também essas três categorias no caso espanhol : velhos e poucos combatentes e militares integraram o ministério de Assuntos exteriores franquista (Fernando Castiella, José María de Areilza), muitos diplomatas vêm da aristocracía tradicional e começaram a carreira diplomática antes da guerra civil (o duque de Alba, o Conde de Casa Miranda, a família Elorza), e os mais jovems integraram o ministério de Assuntos exteriores depois de 1942 (Fernando Morán, Pablo Benavides, Carlos Westendorp) ${ }^{8}$.

Todas essas diferenças podem explicar as posições divergentes nas questões europeias. O fenómeno de geração é muito importante. E essas diferenças vão pouco a pouco diminuir a

\footnotetext{
${ }^{6}$ TOGORES L. E., NEILA HERNÁNDEZ J. L, La Escuela diplomática: cincuenta años de servicio al Estado (1942-1992). Madrid: Escuela diplomática, 1993.

7 TROUVÉ, Matthieu - Les diplomates gaullistes: hommes et réseaux (1944-1981). In AUDIGIER F., LACHAISE B., LAURENT, S. - Les Gaullistes. Hommes et réseaux. Paris: Nouveau monde éditions, 2013, p. 245-259.

${ }^{8}$ TROUVÉ, Matthieu - Les élites diplomatiques espagnoles et la transition démocratique (1975-1982). In COSTE, L., MINVIELlE, S., MOUGEL, F-C. - Le concept d'élites en Europe de l'Antiquité à nos jours. Bordeaux: MSHA, 2014, p. 209-220.
} 
partir dos anos 1970-1980 com a chegada de uma nova geração de diplomatas que só conheceram o contexto da construção europeia.

A participação do país na construção europeia é vista ao mesmo tempo como um fator de paz e uma possibilidade para o país ter mais peso no ambiente das relações internacionais. Para os diplomatas franceses e veteranos da Segunda Guerra mundial ou da Resistência, construir a União europeia e fortalecer o casal franco-alemão é o caminho mais seguro até a prosperidade na Europa occidental e a construção europeia aparece também como um elemento fundamental para manter a paz no contexto de guerra fría.

Do lado espanhol, depois da chamada crise de Munique de 1962, a aproximação à Europa dos Seis é vista como um símbolo de consolidação democrática. Em 1962 toda a oposição política à ditadura franquista se reunía num congresso do Movimento europeu para pedir às autoridades comunitarias não negociarem com Espanha enquanto não houver naquele país um governo democrático ${ }^{9}$. A partir de ahí, a participação da Espanha à construção europeia chegou a fazer parte do discurso democrático e da cultura política espanhola. Essa cultura política foi plenamente integrada pelos diplomatas que serão responsáveis da negociação de ingresso da Espanha na Comunidade europeia : pessoas como Marcelino Oreja, Raimundo Bassols, Fernando Morán, Gabriel Ferrán, Carlos Westendorp, Pedro Solbes, Ángel Viñas. Esses diplomatas também defendem a ideia de que dentro da Comunidade europeia, a Espanha tem mais peso internacional, participa das relações intergovernamentais e das grandes decisões europeias. Essa participação às Comunidades europeias é interpretada como o ato que marca o fim do isolamento internacional espanhol e que simbolicamente significa o reconhecimento da democratização do país ${ }^{10}$.

\section{II- Uma relação à Europa condicionada pelos grandes debates europeus}

As administrações foram confrontadas nos anos 1950-1980 aos debates en torno da construção europeia. Os grandes debates Europa federal / Europa das Patrias, Europa política /

\footnotetext{
9 ÁlVAREZ DE MIRANDA, Fernando - Del « contubernio » de Munich al consenso. Barcelona: Planeta, 1985; SATRÚSTEGUI, J. - Cuando la transición se hizo posible. El « contubernio de Munich ». Madrid: Tecnos, 1993; TOQUERO, José Maria - El contubernio de Munich. Historia 16. N¹42 (1988) p. 12-20.

${ }^{10}$ MORENO JUSTE, Antonio - La administración exterior en la transición de la política exterior española (1975-1986). In TUSELL, J., SOTO, Á. - Historia de la transición y consolidación democrática en España (1975-1986), vol. II. Madrid: UNED, 1996, p. 235-250; MORENO JUSTE, Antonio - España en el proceso de integración europea ». In LA GUARDIA, Ricardo M. de, PÉREZ SÁNCHEZ, Guillermo - Historia de la integración europea. Barcelona: Ariel, 2001, p. 167-214 ; PEREIRA Juan Carlos, Europeización de España / Españolización de Europa : el dilema histórico resuelto. In Documentación Social, n¹11 (1998) p. 39-58.
} 
Europa económica, Europa supranacional / Europa intergovernamental foram no centro das atenções dos diplomatas e as administrações se dividiram em relação à esses conceitos.

No caso francês, os anos 1950 foram marcados pelo debate entre federalistas e antifederalistas $^{11}$. Um grupo reduzido de diplomatas em torno de Robert Schuman - Bernard Clappier, Hervé Alphand - pensaram que a solução de uma Europa federal e supranacional podia ter mais poder, mais força para a defesa da Europa occidental e ser uma garantia contra um eventual perigo alemão. Outros, porém, não queriam que a França fosse se aventurar a abandonar a soberanía : François Seydoux, Jean Chauvel, René Massigli, Christian Fouchet. Esse mesmo debate surge novamente nos anos 1980 na hora de negociar o Ato único de 1986 e o tratado de Maastricht, primeiro passo até a criação da UE.

Outro debate marcante na história da diplomacia francesa com respeito a construção europeia foi aquele que opôs a direção dos assuntos políticos e a direção dos assuntos económicos e financeiros do Quai d'Orsay. Para resumir o debate, a direção dos assuntos políticos tinha uma visão tradicional da Europa, uma visão que pretendía fazer da CEE um ator importante das relações internacionais, enquanto a direção dos assuntos económicos e financeiros composta de técnicos, economistas e tecnócratas tinha uma visão económica da construção europeia fundada nas negociações multilaterais. A direção dos assuntos económicos e financeiros vai ter um papel chave nas questões comunitárias e exercer um monopólio ${ }^{12}$.

Esse debate Europa política / Europa económica - que também traduz outro debate sobre o método relações bilaterais / relações multilaterais - também encontra um éco na Espanha. A partir dos anos 1950, os ministérios do Comércio e dos Assuntos exteriores estão envolvidos numa política de abertura do país, ou tentativa de abertura e de aproximação ao Mercado comum. Em fevereiro de 1962, Espanha pede oficialmente um acordo de associação à Comunidade europeia ${ }^{13}$. A partir desse pedido e até a morte de Franco em 1975, a direção das relações económicas internacionais do ministério dos Assuntos exteriores é o núcleo privilegiado dos funcionários europeistas na Espanha. O ministério dos Assuntos exteriores mostra-se favorável a uma participação da Espanha à construção europeia ao contrario dos

\footnotetext{
${ }^{11}$ ULRICH-PIER, Raphaëlle - Antifédéralistes et fédéralistes: le Quai d'Orsay face à la construction européenne. In CATALA, Michel - Histoire de la construction européenne : Cinquante ans après la déclaration Schuman. Nantes: Presses académiques de l'Ouest, 2001, p. 103-118.

${ }^{12}$ OSMONT, Matthieu - Europe politique versus Europe économique ? Rivalités et répartition des rôles dans les dossiers européens entre la direction des Affaires politiques et la direction des Affaires économiques et financières au Quai d'Orsay (1955-1974). In AFFINITO, M., MIGANI, G., WENKEL, C. - Les deux Europes, Actes du III Colloque international RICHIE. Bruxelles: Peter Lang, 2009, p. 197-212.

${ }^{13}$ MORENO JUSTE, Antonio - Franquismo y construcción europea (1951-1962). Anhelo, necesidad y realidad de la aproximación a Europa. Madrid: Tecnos, 1998.
} 
ministérios técnicos e proteccionistas (Industria, Trabalho, Sindicatos) e do "Movimiento", partido único na ditadura franquista.

Já com a volta da democracia na Espanha com o rey Juan Carlos, outras rivalidades vão surgir. A primeira entre o ministério do Assuntos exteriores e o ministério para as Relações com as Comunidades europeias para saber qual ministério leva a negociação para a integração do país na CEE. O ministério para as Relações com as Comunidades europeias composto por funcionários de horizontes diferentes - técnicos comercias, engenheiros de Estado, engenheiros do sector privado, diplomatas - vai finalmente ser o ator privilegiado das negociações por parte espanhola. Até a chegada dos socialistas de Felipe González, este ministério liderado por Leopoldo Calvo-Sotelo e, depois dele, Eduardo Punset, considera a entrada da Espanha na Comunidade europeia desde um ponto de vista exclusivamente técnico e económico. O discurso do ministério para as Relações com as Comunidades europeias muda com os socialistas a partir de 1982 e torna-se mais político, menos fundado unicamente em critérios económicos e multilaterais ${ }^{14}$.

\section{III- Europa na cultura política dos diplomatas}

René de Saint-Légier, diplomata francês e conselheiro do general de Gaulle entre 1964 e 1968, define o diplomata como um funcionário que não tem um papel executivo, que não participa na formação das decisões, mas que define com sutilez uma posição - ou toma de posição - de um país no âmbito das relações internacionais ${ }^{15}$. Pois, com o presidencialismo dos assuntos internacionais, seja na França com a Quinta República, ou seja na Espanha durante o período da ditadura ou com a volta da democracia, isto é com o fato de que os assuntos internacionais dependem cada vez mais do presidente da República ou do presidente do Governo, a questão da proximidade dos diplomatas com o poder político passa a ser uma questão central. Qual é o nivel de entendimento entre os funcionários diplomáticos e o poder executivo ?

No caso francês, durante o período gaullista (1958-1974), os diplomatas franceses podem concordar com a visão do general de Gaulle da política exterior : independência, grandeza, afirmação da França como potência, política de liderança europeia dentro da

\footnotetext{
${ }^{14}$ TROUVÉ, Matthieu - L'Espagne et l'Europe. De la dictature de Franco à l'Union européenne. Bruxelles: Peter Lang, 2008. 522 p.

${ }^{15}$ Citado por BADEL Laurence - Deux administrations françaises face à la construction européenne : éléments de réflexion pour une histoire politique des administrations. In: Matériaux pour l'histoire de notre temps. $\mathrm{N}^{\circ} 65$ 66 (2002) p. 13-17.
} 
pequena Europa. Através desses temas, constituiu-se uma identidade gaullista na administração do Quai d'Orsay ${ }^{16}$.

Mas isso não significa que todos os diplomatas concordam com as ideias do general de Gaulle. Pelo contrario, as relações entre o chefe do Estado e a administração do ministério das Relações exteriores foi caracterizada pela desconfiança. O Quai d'Orsay tem a fama de ser uma administração independente e a forte presidencialização da política exterior e das questões europeias - “domaine réservé” do presidente da República - a partir de 1958 como a forte centralização das decisões é percebida com bastante preocupação do lado dos diplomatas. E o propio De Gaulle denuncia a mania do compromisso e dos arranjos do Quai d'Orsay ${ }^{17}$.

A diplomacia francesa não concorda com todas as decisões de De Gaulle. René Massigli, por exemplo, que foi delegado para os assuntos exteriores no Comité nacional francês presidido por De Gaulle durante a Segunda Guerra mundial, é partidário de uma relação privilegiada entre a França e a Inglaterra, e ele vai criticar a atitude do chefe do Estado francês frente a candidatura britânica à integração ao Mercado comum ${ }^{18}$. Outros diplomatas como Jean Laloy, Jean-Marie Soutou, Jean Daridan recusam a política francesa da "cadeira vazia" - "politique de la chaise vide" - en 1965 e lamentam a posição de De Gaulle a respeito das reformas institucionais ${ }^{19}$.

No entanto, a maioría do corpo diplomático francês possui uma cultura política de sensibilidade conservadora e as concepções e ideias de política exterior definidas pelo general de Gaulle influenciaram muito as atitudes dos diplomatas franceses frente a CEE. Isso também foi confirmado pelos propios responsáveis da política exterior francesa nos anos 1980. Jacques Chirac e Roland Dumas escrevem em livros de Memórias que os embaixadores são, a maior parte deles, gaullistas e que é difícil de encontrar socialistas ${ }^{20}$. É importante tomar em conta essa observação na hora de entender o posicionamento dos diplomatas com relação a construção europeia. O lema dos diplomatas poderia ser : construir a Europa mas

\footnotetext{
${ }^{16}$ Cf. BADEL, Laurence - Le Quai d'Orsay, la Grande-Bretagne et l'élargissement de la Communauté (19631969). Aspects fonctionnel et culturel. In CATALA, M. - Histoire..., p. 235-260 ; WARLOUZET, Laurent - Le Quai d'Orsay face au traité de Rome. La direction des Affaires économiques et financières (DAEF) de 1957 à 1975. In BADEL, L., JEANNESSON, S., LUDLOW, P. - Les administrations..., p. 139-168 ; OSMONT, Matthieu - Europe politique versus Europe économique ?..., p. 197-212.

${ }^{17}$ PEYREFITTE, Alain - C'était de Gaulle. Paris: Fayard/de Fallois, 1997, tome 2, p. 621-622 e 628.

${ }^{18}$ MASSIGLI, René - Une comédie des erreurs. 1943-1956, Souvenirs et réflexions sur une étape de la construction européenne. Paris: Plon, 1978 ; ULRICH-PIER, Raphaëlle - René Massigli (1888-1988) une vie de diplomatel. Bruxelles: Peter Lang, 2006.

${ }^{19}$ SOUTOU, Jean-Marie - Un diplomate engagé, Mémoires, 1939-1979. Paris: Éditions de Fallois, 2011.

${ }^{20}$ CHIRAC, Jacques - Mémoires 2. Le temps présidentiel. Paris: Nil éditions, 2011, p. 219; DUMAS, Roland Coups et blessures. 50 ans de secrets partagés avec François Mitterrand. Paris: Le Cherche Midi, 2011, p. 213, 215.
} 
sem desfazer a França, isto é, fazer a Europa, impulsar a construção europeia mas sem enfraquecer, descompor ou derrubar a França ${ }^{21}$.

No caso espanhol existem as mesmas ambiguidades. Desde a época moderna dos Habsburgos até o século XX existe uma desconfiança, para não dizer suspeita, do poder real com relação aos diplomatas por causa da suposta independência dos diplomatas, do carácter incontrolável deles, e ao mesmo tempo benevolência, indulgência a respeito de uma elite também considerada como fiel, honesta e indispensável ao funcionamento do Estado ${ }^{22}$. Na maior parte dos casos, os diplomatas se comportaram como servidores do Estado inclusive durante a ditadura franquista, mesmo sem concordar com todas as posições e decisões do chefe de Estado. No entanto, algums diplomatas de tendência demo-cristã e opostos ao socialismo e às ideias de revolução tentaram reformar o Estado por dentro e aceitaram a transição democrática e a solução "Juan Carlos" em 1975. Os diplomatas que se oponem francamente à Franco são uma minoría ${ }^{23}$. Já a partir de 1975 pode-se falar de um amplo consenso da classe política e também do corpo diplomático a favor da entrada da Espanha nas Comunidades europeias.

Agora, os diplomatas espanhóis querem também sobretudo defender os interesses do país dentro da Comunidade europeia : é assim que pode ser interpretada a posição da delegação espanhola tanto durante as negociações de adesão da Espanha na CEE como durante as negociações do tratado de Maastricht. Entre 1986 e 1992, um dos primeiros objetivos da diplomacia foi, efetivamente, tentar preservar os interesses espanhóis e obter ajudas financeiras por parte da Comunidade europeia, como a creação de um fondo de coesão que favoreceu os países menos desenvolvidos da $\mathrm{CEE}^{24}$.

Para concluir, é possível dizer que existem atitudes e reflexos comums entre os diplomatas a respeito da construção europeia. Pouco a pouco os diplomatas franceses e espanhóis integram um discurso sobre Europa na cultura política e administrativa. A pesar dos diplomatas não serem todos a favor da construção europeia, as administrações dos ministérios dos Assuntos exteriores tiveram um papel fundamental na hora de impulsar a construção europeia. Éssa não foi somente uma construção política impulsada pelos grandes pais fundadores, homems políticos ou pelos empresários. É preciso referir-se à todos aqueles que

\footnotetext{
${ }^{21}$ BOSSUAT, Gérard - Faire l'Europe sans défaire la France : 60 ans de politique d'unité européenne des gouvernements et des présidents de la République française (1943-2003). Bruxelles: Peter Lang, 2005.

${ }_{22}$ OZANAM, Didier - Les diplomates espagnols du XVIII siècle. Introduction et répertoire biographique (1700-1808). Madrid-Bordeaux: Casa de Velázquez-Maison des Pays ibériques, 1998.

${ }^{23}$ TROUVÉ, Matthieu - Les élites diplomatiques..., p. 209-220.

${ }^{24}$ TROUVÉ, Matthieu - L'enthousiasme du nouveau venu : la politique européenne de l'Espagne (1979-1992). In DUMOULIN, M., BUSSIÈRE, É., SCHIRMANN, S. - Milieux économiques et intégration européenne au XX siècle : les mutations des années 1980 : 1979-1992. Paris: CHEFF, 2007, p. 183-206.
} 
nos ministérios contribuiram à definição de um posicionamento a favor da integração europeia. 